OPEN ACCESS

Edited by:

Peter Convey,

British Antarctic Survey (BAS),

United Kingdom

Reviewed by:

Katy Morgan

University of Bath, United Kingdom Jinming $\mathrm{Hu}$,

Yunnan University, China

*Correspondence:

Pedro J. Leitão

p.leitao@tu-braunschweig.de

†These authors have contributed equally to this work

Specialty section:

This article was submitted to Biogeography and Macroecology, a section of the journal

Frontiers in Ecology and Evolution

Received: 27 June 2018 Accepted: 11 January 2019

Published: 29 January 2019

Citation:

Leitão PJ and Santos MJ (2019) Improving Models of Species Ecological Niches: A Remote Sensing Overview. Front. Ecol. Evol. 7:9. doi: 10.3389/fevo.2019.00009

\section{Improving Models of Species Ecological Niches: A Remote Sensing Overview}

\author{
Pedro J. Leitão ${ }^{1,2 *}$ and Maria J. Santos ${ }^{3 t}$ \\ ${ }^{1}$ Department Landscape Ecology and Environmental System Analysis, Institute of Geoecology, Technische Universität \\ Braunschweig, Braunschweig, Germany, ${ }^{2}$ Geography Department, Humboldt-Universität zu Berlin, Berlin, Germany, \\ ${ }^{3}$ Üniversity Research Priority Program in Global Change and Biodiversity and Department of Geography, University of Zürich, \\ Zurich, Switzerland
}

Effective conservation capable of mitigating global biodiversity declines require thorough knowledge on species distributions and their drivers. A species ecological niche determines its geographic distribution, and species distribution models (SDMs) can be used to predict them. For various reasons, e.g., the lack of spatial data on relevant environmental factors, SDMs fail to characterize important ecological relationships. We argue that SDMs do not yet include relevant environmental information, which can be measured with remote sensing (RS). RS may benefit SDMs because it provides information on e.g., ecosystem function, health and structure, complete spatial assessment, and reasonable temporal repeat for the processes that determine geographical distributions. However, RS data is still seldom included in such studies with the exception of climate data. Here we provide a guide for researchers aiming to improve their SDM studies, describing how they might include RS data in their specific study. We propose how to improve models of species ecological niches, by including measures of habitat quality (e.g., productivity), nutritional values, and seasonal or life-cycle events. To date, several studies have shown that using ecologically-relevant environmental predictors derived from RS improve model performance and transferability, and better approximate a species ecological niche. These data, however, are not a panacea for SDMs, as there are cases in which RS predictors are not appropriate, too costly, or exhibit low predictive power. The integration of multiple environmental predictors derived from RS in SDMs can thus improve our knowledge on processes driving biodiversity change and improve our capacity for biodiversity conservation.

\footnotetext{
Keywords: ecological niche, species conservation, remote sensing, species distribution (niche) model, ecological theory
}

Global environmental change drives biodiversity changes and declines, and the rearrangement of biotic communities (Pereira et al., 2012; Dirzo et al., 2014). The effects of biodiversity declines may lead to losses in the integrity and functioning of ecosystems and the services they provide, thus potentially putting human well-being at risk (Cardinale et al., 2012). International mitigation programs were established to systematically monitor spatial patterns of species distributions (Schmeller et al., 2015). Species distribution models (SDMs) are empirical statistical approaches that use environmental predictors to estimate the species niche, and from there extrapolate the 
extent of that niche in space to predict the species distribution (Guisan and Zimmermann, 2000), and have become an important tool in conservation science, planning, and management (Elith and Leathwick, 2009; Pecl et al., 2017).

The choice of environmental predictors is fundamental for SDMs; yet, such selection still remains a main source of debate (Synes and Osborne, 2011). Predictors should measure the processes that link environmental conditions to species occurrence, and match the spatial and temporal scales at which such processes occur (Lechner et al., 2012). Therefore, ecologically relevant predictors are capable of generating robust and models transferable to other regions, time periods or conditions. This is particularly relevant when these models are to be used as a base for conservation planning, considering the effects of global change. Predictors may also differ across taxonomic groups, for example soil type might be good predictors for plants, while forest fragmentation, or temperature might be good predictors for animals (Bradley et al., 2012).

Remote sensing (RS) data allow measuring vegetation condition (Turner et al., 2003), ecosystem productivity (Running et al., 2004), seasonality (Reed et al., 1994), all of which might be used in SDMs (He et al., 2015). These measurements are now available over time series (e.g., Landsat time series; Kennedy et al., 2014), thus expanding the possibilities to model species distributions over time. Upcoming sensors are expected to provide even better and more diverse measurements at finer spatial, temporal and spectral resolutions (e.g., Sentinel satellites; Berger and Aschbacher, 2012). The integration of such remotely sensed information in SDMs can lead to global mapping of biodiversity change (Ferrier, 2011), and thus aim at effective conservation actions (Rose et al., 2015).

Although the use of RS in SDMs is widely advocated and applied (Bradley and Fleishman, 2008; Cord et al., 2013), we argue that it's yet to be explored to its full potential. Since the publication of these studies both RS and SDM science has advanced substantially. On the RS side there have been major developments over the last 10 years, namely the continuation of missions and sensors for multispectral data (Sentinel, Landsat 8), novel sensors that provide additional data on ecosystem functioning which could explain geographic distribution patterns (e.g., Flex; Coppo et al., 2017), and the test studies for other upcoming missions (e.g., Guanter et al., 2015; Lee et al., 2015; Stavros et al., 2017; EnMAP, HyspIRI, GEDI). Further data became more easily accessible, in analysisready products, and with higher temporal frequency. On the SDM side new algorithms were developed, algorithms were tested for performance and tools were developed to aid researchers on algorithm selection, as well as on getting a better understanding of the ecological meaning of model outputs. Also on the biological data side, many more records were digitized, there was an emergence of citizen science platforms to collect data, and global analyses for multiple taxonomic groups became possible. In this paper we present our perspective on these advances and provide examples on how the last 10 years of RS and SDM have merged and where could they go into the future.

\section{Improving Models of Species Ecological Niches}

Soberón (2007) proposes that, to realistically reflect the ecology of a species and the spatial scale at which different processes occur, the model that describes its niche should have abiotic variables depicted at low spatial resolution and biotic variables at high spatial resolution, both interacting dynamically. Thus selecting the best RS predictors to model animal species distribution varies if the goal is to understand how abiotic interactions determine a species niche (Grinnellian niche) or how biotic interactions influence it (Eltonian niche). There is growing evidence that land cover classes generally lead to models unsuitable for prediction (Cord et al., 2014), particularly so when used as proxies for habitat quality or resource availability (Bradley and Fleishman, 2008; Vallecillo et al., 2009), although this also depends on the thematic detail of the land cover maps (Cord et al., 2014). Since Bradley and Fleishman (2008), several studies were conducted that took advantage of the existing RS data. Novel approaches have shown progress toward understanding species responses to abiotic conditions such as climate (Austin and van Niel, 2011), nutritional value (Sheppard et al., 2007) or food resources (Coops et al., 2009), and seasonal variation (Leitão et al., 2010).

Several RS datasets are currently available that could measure several niche axes of species, namely: (i) habitat qualitycondition of a habitat type, (ii) nutritional value-food resources available, and (iii) seasonality and life-cycle-temporal variability in habitat due to seasons or individuals, populations and species life-cycles (Gounand et al., 2018). We chose these three niche axes because they capture the most commonly studied aspects of species distribution models and can be more directly measured by RS. In Table 1 we provide examples that either illustrate instances where RS variables have been used to describe these niche axes in animal SDMSDMs studies, or literature where these variables have been suggested as good proxies to do so. Where we are unaware of a study that uses RS variables, we propose a variable (set of variables) and provide the reference describing the variable itself.

Uncritical use of categorical predictors in SDMs has been discouraged (Elith and Leathwick, 2009). Instead, predictors such as vegetation condition and properties (Zimmermann et al., 2007), phenology (Osborne et al., 2001; Leitão et al., 2010) or structure (Bradbury et al., 2005) could be more informative because they may explain availability of resources, shelter, etc. (Coops et al., 2009; Santos et al., 2016). These, together with databases like e.g., PanTHERIA (Jones et al., 2009), COMADRE (Salguero-Gómez et al., 2016), or COMPADRE (Salguero-Gómez et al., 2015) that include a description of species traits could provide good links to what constitutes a species habitat. Adding information on habitat fragmentation could also be an improvement; and there are many metrics available in the ecological literature (Moilanen and Hanski, 2001; Kindlmann and Burel, 2008). Abiotic climatic data can explain a species distribution because climate parameters like temperature and precipitation directly drive physiological processes, such as thermoregulation, and thus affect a species geographic distribution (Kearney and Porter, 2009). Also, given that 
TABLE 1 | Potential RS variables for describing three axes of a species ecological niche: habitat quality, nutritional value, and seasonality and life cycle.

\begin{tabular}{|c|c|c|c|c|c|}
\hline Environmental drivers & RS predictors & Habitat quality & Nutritional value & Seasonality/life cycle & Selected references \\
\hline \multicolumn{6}{|l|}{ SOIL } \\
\hline Soil type & $\begin{array}{l}\text { Spectral features }{ }^{\star} \text {, such as reflectance in the } \\
\text { absorption region of specific constituent } \\
\text { minerals, etc. }\end{array}$ & $\checkmark$ & $\checkmark$ & & Guanter et al., 2015 \\
\hline Soil moisture & $\begin{array}{l}\text { Spectral indices* (e.g., NDWI) or } \\
\text { transformations (e.g., wetness); data from the } \\
\text { SMOS Earth Explorer }\end{array}$ & $\checkmark$ & $\checkmark$ & & Papes et al., 2012 \\
\hline \multicolumn{6}{|l|}{ CLIMATE } \\
\hline Temperature & Thermal data* (LST) & $\checkmark$ & & $\checkmark$ & Cord and Rödder, 2011 \\
\hline Precipitation & $\begin{array}{l}\text { Cloud cover }{ }^{\star} ; \text { precipitation data derived from } \\
\text { CHIRPS }\end{array}$ & $\checkmark$ & $\checkmark$ & $\checkmark$ & Wilson and Jetz, 2016 \\
\hline \multicolumn{6}{|l|}{ VEGETATION } \\
\hline Vegetation structure & $\begin{array}{l}\text { Laser scanning metrics* (e.g., tree height, } \\
\text { canopy height, canopy vertical structure, etc.); } \\
\text { parameters derived from RTM }\end{array}$ & $\checkmark$ & $\checkmark$ & & Bradbury et al., 2005 \\
\hline Vegetation condition & $\begin{array}{l}\text { Spectral indices* (e.g., NDVI, EVI) or } \\
\text { transformations (greenness and brightness); } \\
\text { parameters derived from RTM }\end{array}$ & $\checkmark$ & $\checkmark$ & & Santos et al., 2016 \\
\hline Productivity & $\begin{array}{l}\text { Biophysical parameters }{ }^{*} \text { (e.g., fPAR, LAl); } \\
\text { parameters derived from RTM }\end{array}$ & $\checkmark$ & $\checkmark$ & $\checkmark$ & Coops et al., 2009 \\
\hline Plant stress & $\begin{array}{l}\text { Spectral indices* (e.g., PRI, EWT); fluorescence } \\
\text { data }\end{array}$ & $\checkmark$ & $\checkmark$ & $\checkmark$ & Saatchi et al., 2008 \\
\hline Land surface phenology & $\begin{array}{l}\text { Phenological metrics from time series }{ }^{\star} \text { (e.g., } \\
\text { start/length of the growing season, } \\
\text { senescence, etc.) }\end{array}$ & $\checkmark$ & $\checkmark$ & $\checkmark$ & Leitão et al., 2010 \\
\hline Nutrients & $\begin{array}{l}\text { Spectral features*, such as reflectance in } \\
\text { specific absorption features of nitrogen, etc. }\end{array}$ & $\checkmark$ & $\checkmark$ & & Sheppard et al., 2007 \\
\hline Landscape configuration & $\begin{array}{l}\text { Landscape and surface metrics relating to } \\
\text { fragmentation, connectivity, heterogeneity, } \\
\text { texture*, etc. }\end{array}$ & $\checkmark$ & & $\checkmark$ & Bellis et al., 2008 \\
\hline Habitat information & $\begin{array}{l}\text { Habitat type (LCC), fractional cover* of } \\
\text { functional types (trees, grass, etc.) }\end{array}$ & $\checkmark$ & $\checkmark$ & $\checkmark$ & Wessels et al., 2004 \\
\hline \multicolumn{6}{|l|}{ DISTURBANCES } \\
\hline Disturbances & $\begin{array}{l}\text { Distance metrics* (e.g., to nearest road or } \\
\text { settlement); Change products from LCC or } \\
\text { fractional cover; Indices derived from time } \\
\text { series (e.g., DI) }\end{array}$ & $\checkmark$ & & & Devictor et al., 2008 \\
\hline Human Impact & $\begin{array}{l}\text { Stable nighttime lights* derived from the DMSP, } \\
\text { land use intensity }\end{array}$ & $\checkmark$ & & & Escobar et al., 2015 \\
\hline
\end{tabular}



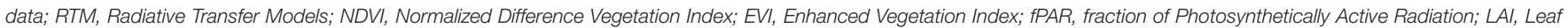


Program. ${ }^{*}$ Denotes which variable is used in the selected reference.

predictors that more directly reflect the species ecology generate transferable models (Austin, 2002), historical reconstructions or extreme climatic events may provide unique real-life experiments and opportunities to test the utility of predictors for model transferability (Randin et al., 2006; Santos et al., 2017). All these approaches can be applicable to RS predictors and integrated in SDMs (Bellis et al., 2008).

In order to characterize habitat quality of a species it is relevant to e.g., explore spectral indices that measure functional aspects of ecosystems (Ustin et al., 2004; Pettorelli et al., 2018), such as the depiction of productivity (e.g., through the Normalized Difference Vegetation Index, NDVI; Santos et al.,
2016). Other properties like canopy water condition and soil properties may also be measured by indices (Table $\mathbf{1}$ ). If one is interested in adding information on vegetation structure, active RS products like active airborne laser scanners (LiDAR) can be an option (Vierling et al., 2008). LiDAR data can be used to measure the vertical structure of vegetation, while satellite RADAR data (from RADARSAT-1 and Sentinel-1) can retrieve vegetation morphology or elevation. Vegetation structural measures can be used directly used as predictors of suitable habitat for wildlife species (Bradbury et al., 2005).

If the goal is to understand how nutritional quality affects animal species distributions, then it is important to consider the 

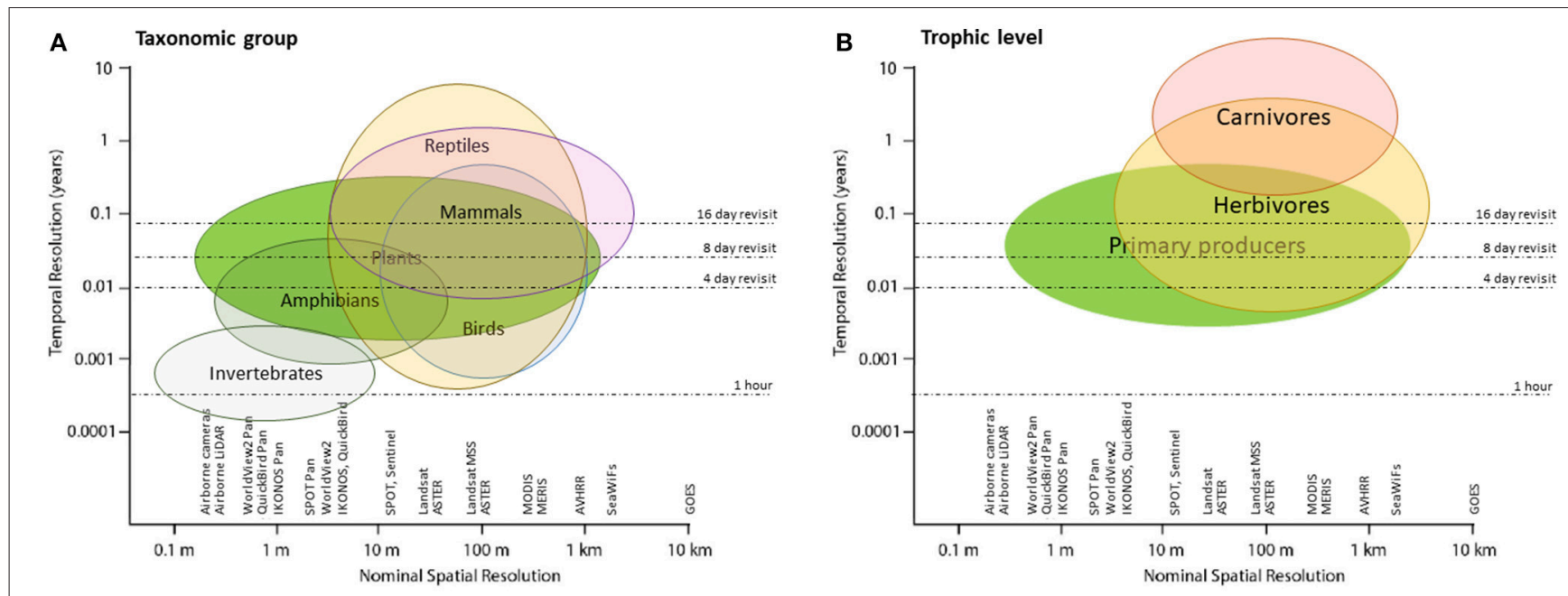

FIGURE 1 | Temporal and spatial resolution of most common remote sensing sensors, and their applicability for generating predictor variables for several biological taxa.

trophic level of the studied species. For example, RS measures of productivity and pigment concentration may be indicators of nutritional quality of plants (Field et al., 1995) or fruiting events for herbivores (Sudbrink et al., 2003). Productivity may also be approximated by fPAR, although forthcoming sensors will be able to measure photosynthetic activity directly. Both of these metrics could be a good proxy of nutritional value for herbivores/granivores (Leitão et al., 2010). For carnivores, productivity might indicate where their prey is and local studies have demonstrated that it improves model performance (Santos et al., 2016).

Finally, if one is interested in how species distributions' may vary seasonally and within a life cycle, time series data on PPAR, vegetation fractional cover, NDVI and Enhanced Vegetation Index (EVI), etc. are becoming more readily available (Bischof et al., 2012). For example, migratory species respond to the greening of the vegetation which determines their migratory patterns (Post et al., 2003; Bischof et al., 2012). Cord and Rödder (2011) demonstrated that the use of multi-temporal RS predictors (EVI and Land Surface Temperature-LST-from MODIS) improved the modeling of the distributions of eight Mexican amphibian species with differing habitat preferences. This is a very promising avenue as it allows modeling changes in species distributions over time, and assessing how vegetation phenology changes might affect habitat quality and migratory and dispersal processes (Post et al., 2003).

\section{Perspectives for Use of RS in SDMs}

RS predictors should not be perceived as a panacea for SDMs, as there are cases where such predictors are not appropriate, too costly, or of low predictive power. In the case of species with small ranges (e.g., amphibians with restricted distribution in mountain tops) satellite data may not provide good coverage, and acquisition and processing of airborne or drone hyperspectral or laser scanning data might be too costly. Models for different species likely require different predictors, for example, NDVI might be a good predictor for herbivores (Kuemmerle et al., 2014), but not for carnivores (Bradley et al., 2012). However, for plants the choice of NDVI as a predictor is contested, some authors argue that it should not be included as it is correlated with plant productivity (Bradley et al., 2012), while others argue that it is a measure of ecosystem functioning and therefore indicates the relation between productivity and biodiversity. Further a RS image is a snapshot and may not always precisely capture the variability in niche conditions of a species. RS predictors tend to be highly correlated and depending on the modeling algorithm used, it may pick the "wrong" ones that lack ecological significance (Dormann et al., 2013).

There are trade-offs between RS systems, as high resolution in one dimension often comes at the cost of other dimensions; for example, high temporally resolved MODIS data come at a coarse spatial and moderate spectral resolution. It is also important to acknowledge that an index from one sensor may not correspond exactly to that same index from another sensor (see Figure 1). For example, a model calibrated from one sensor's NDVI is not easily applied to NDVI from another sensor (Roy et al., 2016). Efforts exist within the RS community to calibrate indices across sensors for wider use (Roy et al., 2016), prompted by the recent increase in availability of free and open access satellite imagery (e.g., Sentinel, Landsat, SPOT). The next generation sensors have reheated the effort toward harmonization and intrinsic transferability of multi-sensor data (Wulder et al., 2015). Similarly, consistency in time series within the same sensor needs to be properly calibrated (van Leeuwen et al., 2006). Achieving consistent environmental predictors would potentially allow a generalized and transferable use and development of SDMs.

Novel RS products increase the array of possible predictors to use in SDMs. Novel off-the-shelf RS products which relate to ecosystem processes illustrate well an increasing communication between what ecologists need and what the RS community can provide (Buchanan et al., 2015). Space agencies and 
satellite data providers increasingly deliver higher-level products for use in SDMs and therefore minimize the requirement of users to know the details about data processing. Recent and forthcoming satellites, for example hyperspectral sensors such as the Environmental Mapping and Analysis Program (EnMAP) HyperSpectral Imager (HSI; Guanter et al., 2015) or the Hyperspectral InfraRed Imager (HyspIRI; Lee et al., 2015) will allow novel ways to measure physiological properties of vegetation, such as water stress, cellulose or nitrogen contents, or nutrient stress (Leitão et al., 2015). New sensors for chlorophyll fluorescence, such as FLORIS onboard the planned FLEX mission (Coppo et al., 2017), will be able to measure photosynthetic activity directly. The planned BIOMASS radar mission (Le Toan et al., 2011) aims at mapping forest biomass on a global scale.

SDM's themselves include a set of limitations, such as assuming equilibrium between the species and the environment, failing to include the potential for evolutionary adaptation, omitting species interactions and non-climatic constraints, failing to allow for novel climates or conditions, etc. (Schwartz, 2012), but many of such limitations are beyond our proposal to better integrate RS in SDM. In fact, RS can solve some of the issues and others are SDM specific, and both disciplines should converge in some aspects. For example, here we argue that RS could provide a means to include non-climatic distribution constraints, such as habitat or human impact (e.g., land use intensity; Kleijn et al., 2009).

RS data are well suited to integration in SDMs to predict the response of biodiversity to environmental drivers and provide information to intergovernmental forums like the Intergovernmental Panel on Climate Change (IPCC) and the Intergovernmental Science-Policy Platform on Biodiversity and

\section{REFERENCES}

Austin, M. P. (2002). Spatial prediction of species distribution: an interface between ecological theory and statistical modelling. Ecol. Modell. 157, 101-118. doi: 10.1016/S0304-3800(02)00205-3

Austin, M. P., and van Niel, K. P. (2011). Improving species distribution models for climate change studies: variable selection and scale. J. Biogeogr. 38, 1-8. doi: 10.1111/j.1365-2699.2010.02416.x

Bellis, L. M., Pidgeon, A. M., Radeloff, V. C., St-Louis, V., Navarro, J. L., and Martella, M. B. (2008). Modeling habitat suitability for Greater Rheas based on satellite image texture. Ecol. Appl. 18, 1956-1966. doi: 10.1890/070243.1

Berger, M., and Aschbacher, J. (2012). Preface: the sentinel missionsnew opportunities for science. Remote Sens. Environ. 120, 1-2. doi: 10.1016/j.rse.2011.12.026

Bischof, R., Loe, L. E., Meisingset, E. L., Zimmermann, B., Moorter, B. V., and Mysterud, A. (2012). A migratory northern ungulate in the pursuit of spring: jumping or surfing the Green Wave? Am. Nat. 180, 407-424. doi: $10.1086 / 667590$

Bradbury, R. B., Hill, R. A., Mason, D. C., Hinsley, S. A., Wilson, J. D., Balzter, H., et al. (2005). Modelling relationships between birds and vegetation structure using airborne LiDAR data: a review with case studies from agricultural and woodland environments. IBIS 147, 443-352. doi: 10.1111/j.1474-919x.2005.00438.x

Bradley, B. A., and Fleishman, E. (2008). Can remote sensing of land cover improve species distribution modelling? J. Biogeogr. 35, 1158-1159. doi: 10.1111/j.1365-2699.2008.01928.x
Ecosystem Services (IPBES). RS for biodiversity has become a priority and has been acknowledged by many international efforts, e.g., Aichi Biodiversity Targets, Sustainable Development Goals, Group on Earth Observation Biodiversity Observation Network, and Essential Biodiversity Variables (Pereira et al., 2013; Skidmore et al., 2015; Pettorelli et al., 2016). These are all strong arguments for accepting the challenge of finding a set of ecologically relevant RS predictors that may be used to globally understand biodiversity change (Ferrier, 2011; Jetz et al., 2016).

\section{AUTHOR CONTRIBUTIONS}

All authors listed have made a substantial, direct and intellectual contribution to the work, and approved it for publication.

\section{FUNDING}

This study was partly funded and/or supported by the German Aerospace Centre (DLR)-Project Management Agency, granted by the German Federal Ministry for Economic Affairs and Energy (BMWi grant 50EE1309) within the research activities of the EnMAP Scientific Advisory Group (EnSAG), the 2015-2016 BiodivERsA COFUND call for research proposals, with the national funder German Federal Ministry of Education and Research (BMBF; project GreenFutureForest, grant 01LC1610A), the Department of Innovation, Environmental and Energy Sciences at Utrecht University in the Netherlands, and the University Research Priority Program in Global Change and Biodiversity at the University of Zürich.
Bradley, B. A., Olsson, A. D., Wang, O., Dickson, B. G., Pelech, L., Sesnie, S. E., et al. (2012). Species detection vs. habitat suitability: are we biasing habitat suitability models with remotely sensed data? Ecol. Modell. 244, 57-64. doi: 10.1016/j.ecolmodel.2012.06.019

Buchanan, G. M., Brink, A. B., Leidner, A. K., Rose, R., and Wegmann, M. (2015). Advancing terrestrial conservation through remote sensing. Ecol. Inform. 30, 318-321. doi: 10.1016/j.ecoinf.2015.05.005

Cardinale, B. J., Duffy, J. E., Gonzalez, A., Hooper, D. U., Perrings, C., Venail, P., et al. (2012). Biodiversity loss and its impact on humanity. Nature 486, 59-67. doi: 10.1038/nature11148

Coops, N. C., Waring, R. H., Wulder, M. A., Pidgeon, A. M., and Radeloff, V. C. (2009). Bird diversity: a predictable function of satellite-derived estimates of seasonal variation in canopy light absorbance across the United States. J. Biogeogr. 36, 905-918. doi: 10.1111/j.1365-2699.2008.02053.x

Coppo, P., Taiti, A., Pettinato, L., Francois, M., Taccola, M., and Drusch, M. (2017). Fluorescence imaging spectrometer (FLORIS) for ESA FLEX mission. Remote Sens. 9:649. doi: 10.3390/rs9070649

Cord, A., and Rödder, D. (2011). Inclusion of habitat availability in species distribution models through multi-temporal remote-sensing data? Ecol. Appl. 21, 3285-3298. doi: 10.1890/11-0114.1

Cord, A. F., Klein, D., Mora, F., and Dech, S. (2014). Comparing the suitability of classified land cover data and remote sensing variables for modeling distribution patterns of plants. Ecol. Modell. 272, 129-140. doi: 10.1016/j.ecolmodel.2013.09.011

Cord, A. F., Meentemeyer, R. K., Leitão, P. J., and Václavík, T. (2013). Modelling species distributions with remote sensing data: bridging disciplinary perspectives. J. Biogeogr. 40, 2226-2227. doi: 10.1111/jbi.12199 
Devictor, V., Julliard, R., and Jiguet, F. (2008). Distribution of specialist and generalist species along spatial gradients of habitat disturbance and fragmentation. Oikos 117, 507-514. doi: 10.1111/j.0030-1299.2008.16215.x

Dirzo, R., Young, H. S., Galetti, M., Ceballos, G., Isaac, N. J., and Collen, B. (2014). Defaunation in the anthropocene. Science 345, 401-406. doi: $10.1126 /$ science. 1251817

Dormann, C. F., Elith, J., Bacher, S., Buchmann, C., Carl, G., Carré, G., et al. (2013). Collinearity: a review of methods to deal with it and a simulation study evaluating their performance. Ecography 36, 27-46. doi: 10.1111/j.1600-0587.2012.07348.x

Elith, J., and Leathwick, J. R. (2009). Species distribution models: ecological explanation and prediction across space and time. Ann. Rev. Ecol. Evol. Systemat. 40, 677-697. doi: 10.1146/annurev.ecolsys.110308.1 20159

Escobar, L. E., Awan, M. N., and Qiao, H. J. (2015). Anthropogenic disturbance and habitat loss for the red-listed Asiatic black bear (Ursus thibetanus): using ecological niche modeling and nighttime light satellite imagery. Biol. Conserv. 191, 400-407. doi: 10.1016/j.biocon.2015.06.040

Ferrier, S. (2011). Extracting more value from biodiversity change observations through integrated modeling. Bioscience 61, 96-97. doi: 10.1525/bio.2011.61.2.2

Field, C. B., Randerson, J. T., and Malmström, C. M. (1995). Global net primary production: combining ecology and remote sensing. Remote Sens. Environ. 51, 74-88. doi: 10.1016/0034-4257(94)00066-V

Gounand, I., Harvey, E., Little, C. J., and Altermatt, F. (2018). Meta-Ecosystems 2.0: rooting the theory into the field. Trends Ecol. Evol. 33, 36-46. doi: $10.1016 /$ j.tree.2017.10.006

Guanter, L., Kaufmann, H., Segl, K., Chabrillat, S., Förster, S., Rogass, C., et al. (2015). The EnMAP spaceborne imaging spectroscopy mission for earth observation. Remote Sens. 7, 8830-8857. doi: 10.3390/rs70708830

Guisan, A., and Zimmermann, N. E. (2000). Predictive habitat distribution models in ecology. Ecol. Modell. 135, 147-186. doi: 10.1016/S0304-3800(00)00354-9

He, K. S., Bradley, B. A., Cord, A. F., Rocchini, D., Tuanmu, M.-N., Schmidtlein, S., et al. (2015). Will remote sensing shape the next generation of species distribution models? Remote Sens. Ecol. Conserv. 1, 4-18. doi: 10.1002/rse2.7

Jetz, W., Cavender-Bares, J., Pavlick, R., Schimel, D., Davis, F. W., Asner, G. P., et al. (2016). Monitoring plant functional diversity from space. Nat. Plants 2:16024. doi: 10.1038/nplants.2016.24

Jones, K. E., Bielby, J., Cardillo, M., Fritz, S. A., O’Dell, J., Orme, C. D. L., et al. (2009). PanTHERIA: a species-level database of life history, ecology, and geography of extant and recently extinct mammals. Ecology 90:2648. doi: 10.1890/08-1494.1

Kearney, M., and Porter, W. (2009). Mechanistic niche modelling: combining physiological and spatial data to predict species' ranges. Ecol. Lett. 12, 334-350. doi: 10.1111/j.1461-0248.2008.01277.x

Kennedy, R. E., Andrefouet, S., Cohen, W. B., Gomez, C., Griffiths, P., Hais, M., et al. (2014). Bringing an ecological view of change to Landsat-based remote sensing. Front. Ecol. Environ. 12, 339-346. doi: 10.1890/130066

Kindlmann, P., and Burel, F. (2008). Connectivity measures: a review. Landsc. Ecol. 23, 879-890. doi: 10.1007/s10980-008-9245-4

Kleijn, D., Kohler, F., Báldi, A., Batáry, P., Concepción, E. D., Clough, Y., et al. (2009). On the relationship between farmland biodiversity and land-use intensity in Europe. Proc. R. Soc. B Biol. Sci. 276, 903-909. doi: 10.1098/rspb.2008.1509

Kuemmerle, T., Baskin, L., Leitão, P. J., Prishchepov, A. V., Thonicke, K., and Radeloff, V. C. (2014). Potential impacts of oil and gas development and climate change on migratory reindeer calving grounds across the Russian Arctic. Divers. Distribut. 20, 416-429. doi: 10.1111/ddi. 12167

Le Toan, T., Quegan, S., Davidson, M. W. J., Balzter, H., Paillou, P., Papathanassiou, K., et al. (2011). The BIOMASS mission: mapping global forest biomass to better understand the terrestrial carbon cycle. Remote Sens. Environ. 115, 2850-2860. doi: 10.1016/j.rse.2011.03.020

Lechner, A. M., Langford, W. T., Bekessy, S. A., and Jones, S. D. (2012). Are landscape ecologists addressing uncertainty in their remote sensing data? Landsc. Ecol. 27, 1249-1261. doi: 10.1007/s10980-012-9791-7

Lee, C. M., Cable, M. L., Hook, S. J., Green, R. O., Ustin, S. L., Mandl, D. J., et al. (2015). An introduction to the NASA Hyperspectral Infrared Imager
(HyspIRI) mission and preparatory activities. Remote Sens. Environ. 167, 6-19. doi: 10.1016/j.rse.2015.06.012

Leitão, P. J., Moreira, F., and Osborne, P. E. (2010). Breeding habitat selection by steppe birds in Castro Verde: a remote sensing and advanced statistics approach. Ardeola 57, 93-116.

Leitão, P. J., Schwieder, M., Suess, S., Okujeni, A., Galvão, L. S., van der Linden, S., et al. (2015). Monitoring natural ecosystem and ecological gradients: perspectives with EnMAP. Remote Sensing 7, 13098-13119. doi: $10.3390 /$ rs71013098

Moilanen, A., and Hanski, I. (2001). On the use of connectivity measures in spatial ecology. Oikos 95, 147-151. doi: 10.1034/j.1600-0706.2001.950116.x

Osborne, P. E., Alonso, J. C., and Bryant, R. G. (2001). Modelling landscape-scale habitat use using GIS and remote sensing: a case study with great bustards. J. Appl. Ecol. 38, 458-471. doi: 10.1046/j.1365-2664.2001.00604.x

Papes, M., Peterson, A. T., and Powell, G. V. N. (2012). Vegetation dynamics and avian seasonal migration: clues from remotely sensed vegetation indices and ecological niche modelling. J. Biogeogr. 39, 652-664. doi: 10.1111/j.1365-2699.2011.02632.x

Pecl, G. T., Araújo, M. B., Bell, J. D., Blanchard, J., Bonebrake, T. C., Chen, I. C., et al. (2017). Biodiversity redistribution under climate change: impacts on ecosystems and human well-being. Science 355:eaai9214. doi: $10.1126 /$ science.aai9214

Pereira, H. M., Ferrier, S., Walters, M., Geller, G. N., Jongman, R. H., Scholes, R. J., et al. (2013). Essential biodiversity variables. Science 339, 277-278. doi: $10.1126 /$ science. 1229931

Pereira, H. M., Navarro, L. M., and Martins, I. S. (2012). Global biodiversity change: the bad, the good, and the unknown. Annu. Rev. Environ. Resour. 37, 25-50. doi: 10.1146/annurev-environ-042911-093511

Pettorelli, N., Schulte to Bühne, H., Tulloch, A., Dubois, G., Macinnis-Ng, C., Queirós, A. M., et al. (2018). Satellite remote sensing of ecosystem functions: opportunities, challenges and way forward. Remote Sens. Ecol. Conserv. 4, 71-93. doi: 10.1002/rse2.59

Pettorelli, N., Wegmann, M., Skidmore, A., Mücher, S., Dawson, T. P., Fernandez, M., et al. (2016). Framing the concept of satellite remote sensing essential biodiversity variables: challenges and future directions. Remote Sens. Ecol. Conserv. 2, 122-131. doi: 10.1002/rse2.15

Post, E., Bøving, P. S., Pedersen, C., and MacArthur, M. A. (2003). Synchrony between caribou calving and plant phenology in depredated and nondepredated populations. Can. J. Zool. 81, 1709-1714. doi: 10.1139/z03-172

Randin, C. F., Dirnbock, T., Dullinger, S., Zimmermann, N. E., Zappa, M., and Guisan, A. (2006). Are niche-based species distribution models transferable in space. J. Biogeogr. 33, 1689-1703. doi: 10.1111/j.1365-2699.2006.01466.x

Reed, B. C., Brown, J. F., Vanderzee, D., Loveland, T. R., Merchant, J. W., and Ohlen, D. O. (1994). Measuring phenological variability from satellite imagery. J. Veget. Sci. 5, 703-714. doi: 10.2307/3235884

Rose, R. A., Byler, D., Eastman, J. R., Fleishman, E., Geller, G., Goetz, S., et al. (2015). Ten ways remote sensing can contribute to conservation. Conserv. Biol. 29, 350-359. doi: 10.1111/cobi.12397

Roy, D. P., Kovalskyy, V., Zhang, H. K., Vermote, E. F., Yan, L., Kumar, S. S., et al. (2016). Characterization of Landsat-7 to Landsat- 8 reflective wavelength and normalized difference vegetation index continuity. Remote Sens. Environ. 185, 57-70. doi: 10.1016/j.rse.2015.12.024

Running, S. W., Nemani, R. R., Heinsch, F. A., Zhao, M. S., Reeves, M., and Hashimoto, H. (2004). A continuous satellite-derived measure of global terrestrial primary production. Bioscience 54, 547-560. doi: 10.1641/00063568(2004)054[0547:ACSMOG]2.0.CO;2

Saatchi, S., Buermann, W., ter Steege, H., Mori, S., and Smith, T. B. (2008). Modeling distribution of Amazonian tree species and diversity using remote sensing measurements. Remote Sens. Environ. 112, 2000-2017. doi: 10.1016/j.rse.2008.01.008

Salguero-Gómez, R., Jones, O. R., Archer, C. R., Bein, C., Buhr, H., Farack, C., et al. (2016). COMADRE: a global data base of animal demography. J. Anim. Ecol. 85, 371-384. doi: 10.1111/1365-2656.12482

Salguero-Gómez, R., Jones, O. R., Archer, C. R., Buckley, Y. M., CheCastaldo, J., Caswell, H., et al. (2015). The compadre plant matrix database: an open online repository for plant demography. J. Ecol. 103, 202-218. doi: $10.1111 / 1365-2745.12334$ 
Santos, M. J., Rosalino, L. M., Santos-Reis, M., and Ustin, S. L. (2016). Testing remotely-sensed predictors of meso-carnivore habitat use in Mediterranean ecosystems. Landsc. Ecol. 31, 1763-1780. doi: 10.1007/s10980-016-0360-3

Santos, M. J., Smith, A. B., Thorne, J. H., and Moritz, C. (2017). The relative influence of change in habitat and climate on elevation range limits in small mammals in Yosemite National Park, California, U.S.A. Clim. Change Responses 4:7. doi: 10.1186/s40665-017-0035-6

Schmeller, D. S., Julliard, R., Bellingham, P. J., Bohm, M., Brummitt, N., Chiarucci, A., et al. (2015). Towards a global terrestrial species monitoring program. J. Nat. Conserv. 25, 51-57. doi: 10.1016/j.jnc.2015.03.003

Schwartz, M. W. (2012). Using niche models with climate projections to inform conservation management decisions. Biol. Conserv. 155, 149-156. doi: 10.1016/j.biocon.2012.06.011

Sheppard, J. K., Lawler, I. R., and Marsh, H. (2007). Seagrass as pasture for seacows: landscape-level dugong habitat evaluation. Estuar. Coast. Shelf Sci. 71, 117-132. doi: 10.1016/j.ecss.2006.07.006

Skidmore, A. K., Pettorelli, N., Coops, N. C., Geller, G. N., Hansen, M., Lucas, R., et al. (2015). Agree on biodiversity metrics to track from space. Nature 523, 403-405. doi: 10.1038/523403a

Soberón, J. (2007). Grinnellian and Eltonian niches and geographic distributions of species. Ecol. Lett. 10, 1115-1123. doi: 10.1111/j.1461-0248.2007.01107.x

Stavros, E. N., Schimel, D., Pavlick, R., Serbin, S., Swann, A., Duncanson, L., et al. (2017). ISS observations offer insights into plant function. Nat. Ecol. Evol. 1:0194. doi: 10.1038/s41559-017-0194

Sudbrink, D. L., Harris, F. A., Robbins, J. T., English, P. J., and Willers, J. L. (2003). Evaluation of remote sensing to identify variability in cotton plant growth and correlation with larval densities of beet armyworm and cabbage loper (Lepidoptera:Noctuidae). Florida Entomol. 86, 290-294. doi: 10.1653/ 0015-4040(2003)086[0290:EORSTI]2.0.CO;2

Synes, N. W., and Osborne, P. E. (2011). Choice of predictor variables as a source of uncertainty in continental-scale species distribution modelling under climate change. Glob. Ecol. Biogeogr. 20, 904-914. doi: 10.1111/j.1466-8238.2010.00635.x

Turner, W., Spector, S., Gardiner, N., Fladeland, M., Sterling, E., and Steininger, M. (2003). Remote sensing for biodiversity science and conservation. Trends Ecol. Evol. 18, 306-314. doi: 10.1016/S0169-5347(03)00070-3

Ustin, S. L., Roberts, D. A., Gamon, J. A., Asner, G. P., and Green, R. O. (2004). Using imaging spectroscopy to study ecosystem processes and properties.
Bioscience 54, 523-534. doi: 10.1641/0006-3568(2004)054[0523:UISTSE]2.0. $\mathrm{CO} ; 2$

Vallecillo, S., Brotons, L., and Thuiller, W. (2009). Dangers of predicting bird species distributions in response to land-cover changes. Ecol. Appl. 19, 538-549. doi: 10.1890/08-0348.1

van Leeuwen, W. J. D., Orr, B. J., Marsh, S. E., and Herrmann, S. M. (2006). Multi-sensor NDVI data continuity: uncertainties and implications for vegetation monitoring applications. Remote Sens. Environ. 100, 67-81. doi: 10.1016/j.rse.2005.10.002

Vierling, K. T., Vierling, L. A., Gould, W. A., Martinuzzi, S., and Clawges, R. M. (2008). Lidar: shedding new light on habitat characterization and modeling. Front. Ecol. Environ. 6, 90-98. doi: 10.1890/070001

Wessels, K. J., De Fries, R. S., Dempewolf, J., Anderson, L. O., Hansen, A. J., Powell, S. L., et al. (2004). Mapping regional land cover with MODIS data for biological conservation: examples from the Greater Yellowstone Ecosystem, USA and Para State, Brazil. Remote Sens. Environ. 92, 67-83. doi: 10.1016/j.rse.2004.05.002

Wilson, A. M., and Jetz, W. (2016). Remotely sensed high-resolution global cloud dynamics for predicting ecosystem and biodiversity distributions. PLoS Biol. 14:e1002415. doi: 10.1371/journal.pbio.1002415

Wulder, M. A., Hilker, T., White, J. C., Coops, N. C., Masek, J. G., Pflugmacher, D., et al. (2015). Virtual constellations for global terrestrial monitoring. Remote Sens. Environ. 170, 62-76. doi: 10.1016/j.rse.2015.09.001

Zimmermann, N. E., Edwards T. C., Moisen, G. G., Frescino, T. S., and Blackard, J. A. (2007). Remote sensing-based predictors improve distribution models of rare, early successional and broadleaf tree species in Utah. J. Appl. Ecol. 44, 1057-1067. doi: 10.1111/j.1365-2664.2007.01348.x

Conflict of Interest Statement: The authors declare that the research was conducted in the absence of any commercial or financial relationships that could be construed as a potential conflict of interest.

Copyright (c) 2019 Leitão and Santos. This is an open-access article distributed under the terms of the Creative Commons Attribution License (CC BY). The use, distribution or reproduction in other forums is permitted, provided the original author(s) and the copyright owner(s) are credited and that the original publication in this journal is cited, in accordance with accepted academic practice. No use, distribution or reproduction is permitted which does not comply with these terms. 